\title{
Association between Friends' Use of Nicotine and Cannabis and Intake of Both Substances among Adolescents
}

\author{
Rachel Herold ${ }^{1}$, Rachel Boykan ${ }^{1, *(\mathbb{D})}$, Allison Eliscu ${ }^{1}$, Héctor E. Alcalá ${ }^{2}$ and Maciej L. Goniewicz ${ }^{3} \mathbb{D}$ \\ 1 Department of Pediatrics, T 11-040, Renaissance School of Medicine at Stony Brook University, \\ Stony Brook, NY 11794, USA; rachel.herold@stonybrookmedicine.edu (R.H.); \\ Allison.Eliscu@stonybrookmedicine.edu (A.E.) \\ 2 Department of Family, Population and Preventive Medicine, \\ Renaissance School of Medicine at Stony Brook University, Stony Brook, NY 11794, USA; \\ hector.alcala@stonybrookmedicine.edu \\ 3 Department of Health Behavior, Division of Cancer Prevention and Population Sciences, \\ Roswell Park Comprehensive Cancer Center, Elm and Carlton Streets, Buffalo, NY 14263, USA; \\ maciej.goniewicz@roswellpark.org \\ * Correspondence: rachel.boykan@stonybrookmedicine.edu; Tel.: +1-631-444-7692; Fax: +1-631-444-7292
}

Citation: Herold, R.; Boykan, R.; Eliscu, A.; Alcalá, H.E.; Goniewicz, M.L. Association between Friends' Use of Nicotine and Cannabis and Intake of Both Substances among Adolescents. Int. J. Environ. Res. Public Health 2021, 18, 695. https:// doi.org/10.3390/ijerph18020695

Received: 18 December 2020 Accepted: 13 January 2021 Published: 15 January 2021

Publisher's Note: MDPI stays neutral with regard to jurisdictional clai$\mathrm{ms}$ in published maps and institutional affiliations.

Copyright: (C) 2021 by the authors. Licensee MDPI, Basel, Switzerland. This article is an open access article distributed under the terms and conditions of the Creative Commons Attribution (CC BY) license (https:// creativecommons.org/licenses/by/ $4.0 /)$.

\begin{abstract}
Nicotine and cannabis use are common among adolescents and may be associated with behavioral problems, poor academic outcomes and use disorders. The goals of this analysis were the following: (1) Describe the influence of friends' nicotine and cannabis smoking and vaping on self-reported use. (2) Describe the relationship between friends' nicotine and cannabis use on participants' urinary biomarkers of nicotine (cotinine) and cannabis (11-nor-9-carboxy$\Delta^{9}$ tetrahydrocannabinol=THC-COOH). This is a secondary analysis of survey and biomarker data collected in adolescents aged 12-21 between April 2017 and April 2018, in Long Island, New York. Bivariate and multivariable analyses were conducted using SPSS 26 . A cutoff value of $\geq 10 \mathrm{ng} / \mathrm{mL}$ was used to signify recent usage for urinary cotinine and THC-COOH levels. Over one-third of the 517 surveyed adolescents reported using tobacco and one-third reported using cannabis. A significant relationship between friends' substance use and self-use was found. For both tobacco and cannabis, over $90 \%(p<0.01)$ of participants with urinary biomarker levels above cutoff had friends who used the respective substance. Friends' nicotine and friends' cannabis use were each independently associated with urinary biomarker levels for those substances (for nicotine, beta $=88.29, p=0.03$; for cannabis, beta $=163.58, p=0.03$ ). Friends' use of nicotine and cannabis is associated with adolescents' intake, as well as the physiological exposure to those substances. These findings underscore the importance of including peer influence in the discussion with adolescents about tobacco and cannabis use.
\end{abstract}

Keywords: tobacco; cannabis; marijuana; peer group; adolescent; biomarkers

\section{Introduction}

Nicotine and cannabinoids, two of the most commonly used substances by adolescents, are primarily delivered by inhalation either from smoked products or vaping devices (e-cigarettes). In 2020, almost $20 \%$ of high-school students were current (past-month) e-cigarette users; most reported vaping nicotine-containing products [1]. In 2019, 22\% of high-school seniors were current cannabis users, and $14 \%$ had vaped cannabis in the past month [2]. While the long-term effects of vaping nicotine are still unclear, adolescent use of nicotine is associated with behavioral problems, depression, anxiety, and an increased risk of nicotine addiction [3]. Adolescents who smoke cannabis are similarly at risk for significant morbidity, including poor academic outcomes and cannabis-use disorder [4-6]. Vaping cannabis may exacerbate this risk, as cannabis formulations used in vaping devices may contain highly concentrated (14-28\%) tetrahydrocannabinol (THC) $[4,7,8]$. 
While the influence of peers on adolescent nicotine and cannabis use is well described [9-11], this association has not been examined using biomarkers. Biomarkers have been used to quantify and confirm self-report. Benowitz et al. found a significant correlation between nicotine and cannabinoid usage patterns and urinary biomarkers (cotinine=nicotine metabolite and THC-COOH=THC metabolite) [12]. We previously reported that adolescent self-reported nicotine and cannabinoid use corresponded to urinary cotinine and THC-COOH levels, and that the co-use of tobacco and cannabis was common and reflected in elevated biomarker levels. Specifically, we found that $55 \%$ of past-week e-cigarette users also used cannabis, and that $67 \%$ of past-week tobacco smokers and $67 \%$ of dual users of combusted tobacco and e-cigarettes used cannabis [13]. We aimed to further examine nicotine and cannabis usage in participants from our previously published study by increasing understanding of the socio-environmental impact on biomarker levels. The goals of this analysis were as follows: (1) Describe the influence of friends' nicotine and cannabis smoking and vaping on self-reported nicotine and cannabis use. (2) Describe the relationship between friends' nicotine and cannabis use on participants' urinary biomarkers of nicotine (cotinine) and cannabis (THC-COOH).

\section{Materials and Methods}

This study is a secondary analysis of survey and biomarker data collected in adolescents, ages 12-21, between April 2017 and April 2018, previously described in detail [13]. Analyses were conducted using SPSS 26. Nicotine and cannabis users were categorized into 5 groups: daily, weekly, monthly, ever and never users. Nicotine use included use of nicotine-containing e-cigarettes or tobacco cigarettes. Cannabis use included any form of cannabinoid (Table 1). The previously established cutoff $(\geq 10 \mathrm{ng} / \mathrm{mL})$ [13], indicating recent (past-week) usage, was applied to urinary cotinine and THC-COOH levels for bivariate analyses (i.e., Pearson chi-square). For multivariable analyses (i.e., multivariable linear regression), continuous measures of cotinine and THC-COOH were used.

Table 1. Questions asked of participants.

\begin{tabular}{c}
\hline Have you ever used an electronic vape product, even one or two times? \\
Why did you try an electronic vape product the first time? \\
\hline When was the last time you used an electronic vape product? \\
\hline Please think about the electronic vape product you most recently used. Does it have nicotine? \\
\hline Do your friends use electronic vape products when you are with them? \\
Have you ever tried cigarette smoking, even one or two puffs? \\
Why did you try cigarettes the first time? \\
When was the last time you smoked a cigarette? \\
\hline Do your friends smoke cigarettes when you are with them? \\
\hline Have you ever used marijuana in any form, even one or two times? \\
Why did you try marijuana the first time? \\
\hline When you use (or used) marijuana does (or did) the product also contain nicotine? last time you used any type of marijuana? \\
\hline Do your friends use marijuana when you are with them?
\end{tabular}

\section{Results}

As Table 2 shows, for this analysis, all 517 participants' surveys were analyzed; a total of 265 had biomarker data. Among all 517 surveyed, over one-third (197/517) reported ever using nicotine (38\%); one in three participants (31\%) reported ever using cannabis. Of ever nicotine users, $37 \%$ reported smoking tobacco and the vast majority reported vaping e-cigarettes (95\%). The majority (91\%) of ever cannabis users smoked and $36 \%$ vaped 
cannabis. Among ever e-cigarette nicotine users, 51\% were past-month users and 23\% were past-week users. Among ever cannabis users (any form), 54\% were past-month and 36\% were past-week users.

Table 2. Sample Characteristics $(n=517)$.

\begin{tabular}{ccc}
\hline & $\boldsymbol{n}$ & Frequency (\%) \\
\hline Ever used nicotine & 197 & 38 \\
Smoked tobacco (among nicotine users) & 72 & 37 \\
\hline \\
Vaped e-cigarettes (among nicotine users) & Ever: 187 & Ever: 95 \\
& Past month: 95 & Past month: 51 \\
Past week: 23 \\
Used cannabis any form & Past week: 43 & Ever: 31 \\
& Ever: 162 & Past month: 54 \\
Smoked cannabis (among cannabis users) & Past week: 58 & Past week: 36 \\
Vaped cannabis (among cannabis users) & 147 & 91 \\
\hline
\end{tabular}

Common reasons for initial nicotine use were curiosity (65\% of tobacco smokers; $69 \%$ of e-cigarette users) and friends' use (39\% of tobacco smokers; $51 \%$ of e-cigarette users). Friends' use was positively associated with self-use of nicotine: $75 \%\left(\chi^{2}{ }_{1}=117.36, p<0.01\right)$ of ever nicotine users and $89 \%\left(\chi^{2}{ }_{1}=4.26, p<0.04\right)$ of past-month nicotine users reported having friends using nicotine (either smoked or vaped). Although curiosity was the most commonly reported reason for initial cannabis use (72\%), $41 \%$ reported friends' use as a reason for first trying cannabis. Chi-square testing revealed a statistically significant relationship between having friends who used cannabis and one's own cannabis use, both ever $\left(71 \%, \chi^{2}{ }_{1}=175.00, p<0.01\right)$ and past-month $\left(82 \%, \chi^{2}{ }_{1}=11.41, p<0.01\right)$.

Almost all (93\%) of participants with cotinine levels above cutoff had friends who used nicotine $\left(\chi^{2}{ }_{1}=21.87, p<0.01\right)$. Multivariable linear regression revealed that friends' use of nicotine was associated with cotinine concentration, when controlling for own nicotine use (Beta $=88.29, p=0.03$ ). Similarly, 90\% of participants with THC-COOH above cutoff had friends who used cannabis $\left(\chi^{2}{ }_{1}=28.13, p<0.01\right)$. Multivariable linear regression revealed that friends' use of cannabis (Beta $=163.58, p=0.03$ ) was associated with THC level, when controlling for own cannabis use.

\section{Discussion}

In this analysis, friends' nicotine and cannabis use were each independently associated with adolescents' self-reported usage of each substance, and with urinary biomarkers. One explanation for this finding may be that friends' nicotine and cannabis use reinforces one's own use behaviors, perhaps leading to more frequent or heavier use of each substance. While we did not quantify time spent with friends or assess attitudes regarding friends' influence, our prior analysis of e-cigarette users in this study group demonstrated higher biomarker levels with more frequent use [13].

It is also possible that the independent effect of friends' nicotine and cannabis use reflects secondhand exposure. Although exposure to secondhand tobacco smoke is associated with the presence of urinary cotinine in adolescents [14], the effect of secondhand nicotine exposure from aerosol (vaping) is less well studied. Similarly, research has shown that measurable levels of urinary THC-COOH can be found after passive exposure to marijuana smoke [15]. With the increasing potency of cannabis products available today and the pervasive use of these substances among adolescents, this potential effect may have more significant implications.

Regardless of the explanation, our findings underscore the important influence of friends' behavior in adolescents' nicotine and cannabis use, and the potential physiologic 
impact of this behavior, particularly in light of the known morbidity associated with the increasingly high concentrations of nicotine and cannabinoids in products used today.

The cross-sectional design of this study limits drawing conclusions beyond association. Additionally, as cannabis users reported using multiple forms of cannabis, we were unable to differentiate the potential influence of different cannabis formulations (e.g., smoked vs. vaped) on friends' use and on biomarker levels. Further study should evaluate whether product type and/or strength contribute to these findings.

\section{Conclusions}

We found that friends' use of nicotine and cannabis were independently associated with adolescents' use of each substance, and this was reflected in urinary biomarker levels. These findings underscore the important influence of friends' behavior in adolescent substance use and physiologic impact. Pediatricians should discuss friends' influence on behavior and physiology when counseling their adolescent patients on the smoking and vaping of both nicotine and cannabis products.

Author Contributions: R.H.: conceptualization, analysis, writing. R.B.: conceptualization, analysis, writing, supervision. A.E.: conceptualization, analysis, writing and editing. H.E.A.: supervision of statistical analysis, review and editing. M.L.G.: conceptualization, analysis, review and editing. All authors have read and agreed to the published version of the manuscript.

Funding: This study was funded by an Intramural Research Grant Award to Boykan from the Department of Pediatrics, Renaissance School of Medicine at Stony Brook University. No additional funding was provided for this analysis.

Institutional Review Board Statement: The original study was conducted according to the guidelines of the Declaration of Helsinki, and approved by the Institutional Review Board of Stony Brook University (protocol code 982331). The additional analysis for this report required no additional approval, as all data collection was complete and deidentified.

Informed Consent Statement: Informed consent was obtained from all subjects involved in the original study.

Data Availability Statement: The data presented in this study are available on request from the corresponding author. The data are not publicly available due to confidentiality of information reported by study participants.

Conflicts of Interest: Goniewicz is supported by the National Cancer Institute (NCI) and FDA Center for Tobacco Products (CTP) under Award Number U54CA228110. The views and opinions expressed in this article are those of the authors and do not necessarily represent the official position of the National Institutes of Health or the Food and Drug Administration.

\section{References}

1. Wang, T.W.; Neff, L.J.; Park-Lee, E.; Ren, C.; Cullen, K.A.; King, B.A. E-cigarette Use Among Middle and High School StudentsUnited States, 2020. MMWR. Morb. Mortal. Wkly. Rep. 2020, 69, 1310-1312.

2. NIDA. Monitoring the Future Survey: High School and Youth Trends Drug Facts. 2020. Available online: https://www. drugabuse.gov/publications/drugfacts/monitoring-future-survey-high-school-youth-trends (accessed on 23 June 2020).

3. United States Public Health Service; Office of the Surgeon General; National Center for Chronic Disease Prevention; Health Promotion (US). Office on Smoking. In Preventing Tobacco Use Among Youth and Young Adults: A Report of the Surgeon General; Centers for Disease Control and Prevention (US): Atlanta, GA, USA, 2012.

4. Volkow, N.D.; Baler, R.D.; Compton, W.M.; Weiss, S.R. Adverse Health Effects of Marijuana Use. N. Engl. J. Med. 2014, 370, 2219-2227. [PubMed]

5. Peters, E.N.; Budney, A.J.; Carroll, K.M. Clinical correlates of co-occurring cannabis and tobacco use: A systematic review. Addiction 2012, 107, 1404-1417. [CrossRef] [PubMed]

6. Pulvers, K.; Ridenour, C.; Woodcock, A.; Savin, M.J.; Holguin, G.; Hamill, S.; Romero, D.R. Marijuana use among adolescent multiple tobacco product users and unique risks of dual tobacco and marijuana use. Drug Alcohol Depend. 2018, 189, 80-89. [CrossRef] [PubMed]

7. ElSohly, M.A.; Mehmedic, Z.; Foster, S.; Gon, C.; Chandra, S.; Church, J.C. Changes in Cannabis Potency Over the Last 2 Decades (1995-2014): Analysis of Current Data in the United States. Biol. Psychiatry 2016, 79, 613-619. [CrossRef] [PubMed] 
8. Stuyt, E. The Problem with the Current High Potency THC Marijuana from the Perspective of an Addiction Psychiatrist. Mo. Med. 2018, 115, 482-486. [PubMed]

9. Perikleous, E.P.; Steiropoulos, P.; Paraskakis, E.; Constantinidis, T.C.; Nena, E. E-Cigarette Use Among Adolescents: An Overview of the Literature and Future Perspectives. Front. Public Health 2018, 6, 86. [CrossRef] [PubMed]

10. Defoe, I.N.; Khurana, A.; Betancourt, L.M.; Hurt, H.; Romer, D. Disentangling longitudinal relations between youth cannabis use, peer cannabis use, and conduct problems: Developmental cascading links to cannabis use disorder. Addiction 2019, 114, 485-493. [CrossRef] [PubMed]

11. Schuler, M.S.; Tucker, J.S.; Pedersen, E.R.; D'Amico, E.J. Relative influence of perceived peer and family substance use on adolescent alcohol, cigarette, and marijuana use across middle and high school. Addict. Behav. 2018, 88, 99-105. [CrossRef] [PubMed]

12. Benowitz, N.L.; Nardone, N.; St.Helen, G.; Addo, N.; Jacob, P.; Liakoni, E.; Jain, S.; Hooshfar, S.; Lynch, K. Quantitative biochemical screening for marijuana use and concordance with tobacco use in urban adolescents. Drug Alcohol Depend. 2019, 205, 107583. [CrossRef] [PubMed]

13. Boykan, R.; Messina, C.R.; Chateau, G.; Eliscu, A.; Tolentino, J.; Goniewicz, M.L. Self-Reported Use of Tobacco, E-cigarettes, and Marijuana Versus Urinary Biomarkers. Pediatrics 2019, 143, e20183531. [CrossRef] [PubMed]

14. Benowitz, N.L.; Nardone, N.; Jain, S.; Dempsey, D.A.; Addo, N.; Helen, G.S.; Jacob, P. Comparison of Urine 4-(Methylnitrosamino)1-(3)Pyridyl-1-Butanol and Cotinine for Assessment of Active and Passive Smoke Exposure in Urban Adolescents. Cancer Epidemiol. Biomark. Prev. 2018, 27, 254-261. [CrossRef] [PubMed]

15. Berthet, A.; De Cesare, M.; Favrat, B.; Sporkert, F.; Augsburger, M.; Thomas, A.; Giroud, C. A systematic review of passive exposure to cannabis. Forensic Sci. Int. 2016, 269, 97-112. [CrossRef] [PubMed] 